\title{
Review on Quality Characteristics of Complementary Food and Look for Policy Gap in Case of Ethiopia
}

\author{
Dechasa Bersissa Seboka \\ Institute of Technology, Food Science and Postharvest Technology Department, Haramaya University, Dire Dawa, Ethiopia
}

\section{Email address:}

soboqr@gmailcom

\section{To cite this article:}

Dechasa Bersissa Seboka. Review on Quality Characteristics of Complementary Food and Look for Policy Gap in Case of Ethiopia. American Journal of Health Research. Vol. 7, No. 4, 2019, pp. 51-58. doi: 10.11648/j.ajhr.20190704.12

Received: June 5, 2019; Accepted: July 11, 2019; Published: August 7, 2019

\begin{abstract}
Malnutrition is the main factor for mortality and morbidity of children in developing countries. In Ethiopia 57\% of death of children under 5 year of age are due to malnutrition. Inappropriate complementary feeding practices and it underlies more than one-third of child mortality in Ethiopia. Baby's growth and development is dependent on the type and amount of nourishment gets. Breast milk and the quality of complementary food play important role in baby's growth. When breast milk is no longer enough to meet the nutritional needs of the infant, complementary foods should be added to the diet of the child. The transition from exclusive breastfeeding to family foods, referred to as complementary feeding, during the period of complementary feeding, children are at high risk of under nutrition. Complementary foods are often of inadequate nutritional quality, or they are given too early or too late, in too small amounts, or not frequently enough. So consuming quality complementary foods should be given. The Guiding principles for complementary feeding of the breast feed child, set standards for developing locally appropriate feeding recommendations. They provide guidance on desired feeding behaviors as well as on the amount, consistency, energy density and nutrient content of foods. For energy, 200, 300, and 550 kcal per day is expected to be covered by complementary foods at 6-8, 9-11, and 12-23 months, respectively In addition, the complementary foods must provide relatively large proportions of micronutrients such as iron, zinc, phosphorus, magnesium, calcium, and vitamin -A. Complementary feeding should be timely, meaning that all infants should start receiving foods in addition to breast milk from 6 months onwards. It should be adequate, meaning that the complementary foods should be given in amounts and consistency and using a variety of foods to cover the nutritional needs of the growing child while maintaining breastfeeding.
\end{abstract}

Keywords: Malnutrition, Complementary Food, Energy

\section{Introduction}

Approximately one-third of children less than five years of age in developing countries demonstrated low height-for-age $(<-2$ SD with respect to reference data) [1]. Adequate nutrition during infancy is essential for lifelong health and wellbeing. Infants should be exclusively breastfed for the first six months of life to achieve optimal growth, development, and health. Thereafter, to meet their evolving nutritional requirements, infants should receive nutritionally adequate and safe complementary foods, while continuing to breastfeed for up to two years or more [2].

The complementary feeding means giving the child other nutritious foods in addition to breast milk [3]. Complementary foods are required to contain adequate protein-energy, vitamins and minerals. Formulated complementary food must be soft, acceptable and contain the essential nutrients in the appropriate proportion to supply the babies need for growth and development [4]. During the weaning period, semi-solid and solid foods are introduced, while breast-feeding continues at a lesser frequency. Complementary food should be the same staple foods for adults, but made in smooth for nourishing, appetizing, acceptable consistency and suitable for babies. It is important that infant meals should contain an adequate quantity of body building food that attractively prepared and served in small quantities [5].

According to [3], a proper complementary feeding consists of foods that are rich in energy and micronutrients especially iron, zinc, calcium, vitamin $\mathrm{A}$, vitamin $\mathrm{C}$ and folates, free of 
contamination (pathogens, toxins or harmful chemicals), no much salt or spices and also easy to prepare from family foods and at a cost that is acceptable by most families. Therefore, this review is to look at the literature and policy guidelines regarding the characteristics of the quality of complementary foods in the case of developing countries such as Ethiopia.

\subsection{Objective}

The general objectives of the review are to review a literature of for the quality nutritional content of complementary food and look for a policy gap.

\subsection{Specific Objectives}

a. To review the guiding principles for complementary feeding of the breastfed child.

b. To review the quality characteristics of complementary food.

\section{Literature Review}

\subsection{Complementary Food}

Complementary foods are defined as any solid or liquid foods with a nutritional value other than breast milk that offered to breast-feed infant [6]. It is the practice of giving infants other foods or fluids than breast milk.

The term weaning literally means taking the infant away from breast and providing nourishment by other means [3]. But as breast milk continues to be an important sources of proteins, Vitamins like A \& C (even for older babies) the use of term weaning is now discarded in favor of complementary feeding. Complementary feeding means giving the child other nutritious foods in addition to breast milk.

\subsection{Complementary Food Feeding Period}

There has recently been some confusion as to the ideal time to introduce complementary foods to an infant. The WHO has suggested that between four to six months is the best time for complementary foods. However, recent reviews of literature suggest that there is no advantage in introducing complementary foods before six months of age, except in individual cases [7].

Infant's aged 6 to 24 months is a critical period for the promotion of adequate nutrition. This is the stage at which there is a higher prevalence of malnutrition and deficiency of certain micronutrients [6].

In the late 1970 s up to 2001 doubt and controversies about the expression of complementary food and proper duration of exclusive breast feeding, during those years the introduction of complementary food is between the fourth and six month, But after the 54th World health assembly, WHO recommended the introduction of complementary food around six month [8].

The new recommendations emphasize the healthy feeding practices, which comprise both the adequate food quantity and quality, including care with food handling, preparation, feeding and storage practices, and the respect and adequacy to the cultural characteristics of each people [8].

The mean age of any solid introduction was 20.3 weeks [9]. United nations Children's fund (UNICEF) World health organization (WHO) recommend in the transition to introducing the child to the family diet, in addition to breastfeeding children age of six months and older should be fed small quantities of solid and semi-solid foods frequently throughout the day. There is no right age when a baby should be weaned. Feeding complementary food too early may cause baby at higher risk of developing digestive disorders and adverse reactions or allergies to certain foods. On the other hand, the application of complementary feeding too late may deprive adequate nutrition and can result in improper growth and development [10].

\subsection{Characteristics of Proper Complementary Food}

A proper complementary feeding consists of foods that are rich in energy and in micronutrients (especially iron, zinc, calcium, vitamin $\mathrm{A}$, vitamin $\mathrm{C}$ and folates), free of contamination (pathogens, toxins or harmful chemicals), without much salt or spices, easy to eat and easily accepted by the infant, in an appropriate amount, easy to prepare from family foods, and at a cost that is acceptable by most families [8].

Appropriate complementary foods can be readily consumed and digested by the young child from six months onwards and provides nutrients - energy, protein, fat and vitamins and minerals - to help meet the growing child's needs in addition to breast milk [11].

\subsubsection{Energy Content}

Minimum number of meals required to attain the level of energy needed from complementary foods with mean energy density of $0.6,0.8$, or $1.0 \mathrm{kcal} / \mathrm{g}$ for children in developing countries with low or average levels of breast milk energy intake [4].

The energy intake for infants younger than two years living in developing countries, with an average breast-milk intake for each age, complementary foods are believed to provide approximately $200 \mathrm{kcal}$ a day from 6 to 8 months of life, $300 \mathrm{kcal}$ from 9 to 11 months and $550 \mathrm{kcal}$ from 12 to 23 months [12].

\subsubsection{Protein Content}

The recommended protein content (grams of protein per $100 \mathrm{kcal}$ of food) for complementary foods is of $0.7 \mathrm{~g} / 100$ $\mathrm{kcal}$, from 5 to 24 months [8]. In most countries, the protein requirements of infants are met when the energy intake is appropriate, except if there is a predominant intake of lowprotein foods (e.g.: sweet potato and cassava). It is of paramount importance that infants eat high-quality and easily digestible proteins, which are found in breast milk and in animal products. Alternatively, high-quality protein can be provided by properly mixing some vegetables or cereals [8].

\subsubsection{Fat Content}

Lipids in complementary foods should provide 
approximately 30 to $45 \%$ of the total energy required, which is enough to guarantee the adequate intake of essential fatty acids, good energy intake, and uptake of fat-soluble vitamins [8].

The Codex standard for processed cereal-based foods for infants and young children [13], recommends that if lipids exceed $3.3 \mathrm{~g}$ fat $/ 100 \mathrm{kcal}$, the level of linoleic acid should not be less than $300 \mathrm{mg}$ per $100 \mathrm{kcal}$ and not exceed $1200 \mathrm{mg}$ per $100 \mathrm{~g}$ of product. If fats are added, use of (poly-) unsaturated) fatty acids is preferred; saturated fatty acids should preferably be less than $10 \%$ of total energy provided by 100 grams of the product or per serving. The use of synthetic trans fats should be avoided: where used they must account for less than $1 \%$ of total energy [4].

\subsubsection{Mineral Content}

At 9-11 months of age, for example, the proportion of the Recommended Nutrient Intake that needs to be supplied by complementary foods is $97 \%$ for iron, $86 \%$ for zinc, $81 \%$ for phosphorus, $76 \%$ for magnesium, $73 \%$ for sodium and $72 \%$ for calcium (Kathryn and Dewey, 2001). But in most developing countries, complementary foods do not provide sufficient iron, zinc.

To meet the nutritional mineral requirements of infants, a variety of mineral-rich complementary foods should be offered, since the consumption of these foods is relatively small among infants/children aged between six and 24 months.

Iron

The recommended iron intake is of $4 \mathrm{mg} / 100 \mathrm{kcal}$ from 6 to 8 months, $2.4 \mathrm{mg} / 100 \mathrm{kcal}$ from 9 to 11 months and 0.8 $\mathrm{mg} / 100 \mathrm{kcal}$ from 12 to 24 months [8]. In developing countries, due to low iron intake and bioavailability (only approximately 11 to $18 \%$ of uptake), iron requirements often cannot be totally met. Infants aged between six and 12 months cannot eat enough iron-rich foods to meet their requirements, in addition to the fact that the price of these foods can be prohibitive to low-income families [8].

Iron supplementation usually ranges $2-4 \mathrm{mg} / \mathrm{kg} /$ day (total intake) and is dependent upon the clinical condition of the infant. Iron supplementation should continue until the infant is at least 12 months corrected age and taking a variety of iron rich complementary food. The infant's Physician or Registered Dietitian will provide guidance as to when iron supplementation should be discontinued (Americans, 2019).

\section{Calcium}

Infants aged 7-12 month obtain an estimated $130 \mathrm{mg}$ calcium from human milk, leaving another $140 \mathrm{mg}$ to be supplied by complementary foods, Children aged 12-23 month obtain an estimated $100 \mathrm{mg}$ calcium from human milk; another $250 \mathrm{mg} / \mathrm{d}$ from food.[15].

\section{Magnesium}

Human milk provides $20-30 \mathrm{mg} / \mathrm{d}$ of magnesium depending on intake level. Solid foods provided to older infants may typically provide $\sim 55 \mathrm{mg} / \mathrm{d}$ of magnesium. Based on these data, a magnesium intake of $75 \mathrm{mg} / \mathrm{d}$ was set as the AI for infants' ages' 7-12 month in the United States, RDA of $80 \mathrm{mg} / \mathrm{d}$ was established by the Food and Nutrition Board (Abrams \& Atkinson, 2018).

Phosphorus

Based on dietary and balance data, the AI of $275 \mathrm{mg} / \mathrm{d}$ was set for phosphorus for infants aged 7-12 month (200 mg from solid foods and $75 \mathrm{mg}$ from human milk) [15].

Zinc

The daily ration of a fortified complementary food should contain $4-5 \mathrm{mg}$ of zinc. This exceeds the RDA of $3 \mathrm{mg}$ and is justified because of the lower bioavailability of zinc in cereal-based diets typical in developing countries. Zinc oxide is the compound most commonly used because it is well absorbed, produces no organoleptic changes and is significantly less expensive than the other zinc compound [4].

Table 1. Energy needed from complementary foods for breastfed and non-breastfed older infants' and young children in developing countries and estimated gastric capacity.

\begin{tabular}{|c|c|c|c|c|c|c|}
\hline \multirow[t]{2}{*}{$\begin{array}{l}\text { Age of child } \\
\text { (month) }\end{array}$} & \multicolumn{2}{|c|}{$\begin{array}{l}\text { Recommended daily feeding } \\
\text { frequency (meals/snacks) }\end{array}$} & \multicolumn{2}{|c|}{ Energy needs from complementary foods } & \multicolumn{2}{|l|}{ Gastric capacity (ml) } \\
\hline & Breastfed & Not breastfed & Breastfed (kcal/day) & Not Breastfed (kcal/day) & Average child ml/meal & Growth retarded child $\mathrm{ml} / \mathrm{meal}$ \\
\hline $6-8$ & $2-3$ & $4-5$ & 200 & 600 & 249 & 192 \\
\hline $9-11$ & $3-4$ & $4-5$ & 300 & 700 & 285 & 228 \\
\hline $12-23$ & $3-4$ & $4-5$ & 550 & 900 & 345 & 273 \\
\hline
\end{tabular}

Source: [12] Guiding principles for complementary feeding of the breast feed child. http://www.who.int/child_adolescent_health/documents/a85622/en/index.html.

Table 2. Dietary Reference Intakes (DRIs): Recommended Dietary Allowances and Adequate Intakes, Elements.

\begin{tabular}{|c|c|c|c|c|c|c|c|}
\hline age & iron & Calcium & magnesium & potassium & Zinc & sodium & phosphorus \\
\hline $0-6$ & 0.27 & 200 & 30 & 100 & 2 & 0.12 & 100 \\
\hline $6-12$ & 11 & 260 & 75 & 275 & 3 & 0.37 & 275 \\
\hline $12-36$ & 7 & 700 & 80 & 3 & 3 & 1 & 460 \\
\hline
\end{tabular}

Source: Food and Nutrition Board, Institute of Medicine, National Academies National Academies Press [16].

\subsubsection{Vitamin Content}

Vitamin A

If the mother's diet has adequate vitamin A content, the offer of vitamin A-rich foods easily meets the requirements of the nursing infant. If the mother lives in a vitamin A deficiency endemic area, she should receive special 
supplementation and her infant should be offered vitamin Arich foods, preferably some-time before or after breastfeeding in order to increase the uptake of carotene and retinol from the diet. The major food sources of vitamin A are liver, egg yolk, milk products, dark green and leafy vegetables and yellow/orange vegetables and fruit (carrots, pumpkin, red peppers, yellow peppers, mango, passion fruit and papaya) [8].

\section{Vitamin D}

Breast milk and complementary foods have very little to contribute to the supply of vitamin D requirements since this vitamin basically depends upon direct exposure of the skin to sunlight.

Vitamin D supplementation is recommended for all in preterm infants at $4000 \mathrm{IU} /$ day (Nutrition guide line, 2015).

\subsection{Guiding Principles for Complementary Feeding of the Breastfed Child}

The guidelines developed from discussions at several technical consultations and documents on complementary feeding (WHO/UNICEF, 1998), WHO/UNICEF Technical Consultation on Infant and Young Child Feeding, (2000), WHO Global Consultation on Complementary Feeding, (2001), Academy for Educational Development, (1997) and Dewey and Brown, (2002) were described in several ways. Duration of exclusive breastfeeding and age of introduction of complementary foods six months of age (180 days) while continuing to breastfeed until two years of age or beyond [12].

Good hygiene and proper food handling by washing caregivers' and children's hands before food preparation and eating, storing foods safely and serving foods immediately after preparation, using clean utensils to prepare and serve food, using clean cups and bowls when feeding children.

The energy needs from complementary foods for infants with "average" breast milk intake in developing countries are approximately $200 \mathrm{kcal}$ per day at 6-8 months of age, 300 kcal per day at 9-11 months of age, and $550 \mathrm{kcal}$ per day at 12-23 months of age. But industrialized countries these estimates differ somewhat $(130,310$ and $580 \mathrm{kcal} / \mathrm{d}$ at $6-8$, 9-11 and 12-23 months, respectively) because of differences in average breast-milk intake [12].

Food consistency and variety as the infant gets older, adapting to the infant's requirements and abilities. Meal frequency and energy density increase as he/she gets older meals of complementary foods should be provided 2-3 times per day at 6-8 months of age and 3-4 times per day at 9-11 and 12-24 months of age. Use of vitamin-mineral supplements or fortified products for infant and mother use fortified complementary foods or vitamin-mineral supplements for the infant, as needed.

Table 3. Older Infants and Young Children reference daily requirements for some vitamins and Minerals (Source. [18]).

\begin{tabular}{ll}
\hline Vitamins Amount/day & \\
\hline Vitamin A ( $\mu$ g retinol equivalents) & 400 \\
Vitamin D ( $\mu$ g retinol equivalents) & 5 \\
\hline
\end{tabular}

\begin{tabular}{ll}
\hline Vitamins Amount/day & \\
\hline Vitamin E (mg) & 5 \\
Vitamin C (mg) & 30 \\
Tiamifla (mg) & 0.5 \\
Riboflavin $(\mathrm{mg})$ & 0.5 \\
Niacin $(\mathrm{mg})$ & 6 \\
Foliate $(\mu \mathrm{g})$ & 150 \\
Vitamin B12 $(\mu \mathrm{g})$ & 1 \\
Calcium $(\mathrm{mg})$ & 500 \\
Iron $(\mathrm{mg})$ & 12 \\
Iodine $(\mu \mathrm{g})$ & 90 \\
Zinc $(\mathrm{mg})$ & 8.3 \\
\hline
\end{tabular}

\subsection{Ethiopian National Strategy for Infant and Young Child Feeding}

In Ethiopia, malnutrition prevalence among children is among the highest in the world. In 2011, an estimated $44 \%$ of children under the age of five were suffering from chronic malnutrition (stunting), and $44 \%$ of children suffered from iron-deficiency anemia [19].

The global strategy for Infant and Young Child Feeding (IYCF) which was held in December 2002 in Harare, Zimbabwe, Ethiopia, Ghana, Zimbabwe, and Botswana outlined a list of policies, strategies, conventions and national plans of action in health and related issues to be prepared. Accordingly it states the guiding principles for national vision to Nutrition, Infant and Child Feeding, This Infant and Young Child Feeding Strategy has been prepared based on the national needs and commitments to improve IYCF practices and follows the WHO Global Strategy for Infant and Young Child Feeding Federal Ministry of Health Family Health Department Ethiopia [20].

As a result it recommends the following:

1. The Optimal period introduction of complementary feeding starts from 6-monthage up to two years of age or beyond.

2. Complementary foods should be safely prepared and stored Good hygiene and proper food handling. Wash caregivers' and children's hands before food preparation and eating, serve food immediately after preparation.

3. The amount of complementary food should be Adequate for child's age. Introduce small amounts of food at 6 months and increase the quantity, as the child gets older, while maintaining frequent breastfeeding.

4. Complementary food should be consistency and variety. Infants can eat pureed, mashed and semi-solid foods beginning at six months. By eight months, most infants can also eat "finger foods" snacks that can be eaten by children alone. By 12 months, most children can eat the same types of foods as consumed by the rest of the family.

5. Ensure meal frequency and energy density. The appropriate number of feedings depends on the energy density of the local foods and the usual amounts consumed at each feeding. Average, healthy breastfed infant, should feed complementary foods 2 to 3 times per day at 6 to 8 months of age and 3-4 times per day from 9-11 months and from 12 to 24 months. 
6. Complementary foods should have adequate nutrient content. Feed Vitamin A-rich foods with fats to increase absorption and citrus fruits with iron- and protein-rich foods to increase absorption. Meat, poultry, fish or eggs should be eaten daily, or as often as possible. Avoid giving drinks with low nutrient value, such as tea, coffee and sugary drinks such as soda.

7. Vitamin-mineral supplements or fortified products be used by the infant and mother, as needed. Breastfeeding (and pregnant) mothers may also need vitamin-mineral supplements or fortified products, both for their own health and to ensure normal concentrations of certain nutrients in their breast milk.

8. Industrially processed complementary foods are an option for those an access to the knowledge to use it. This food products should, meet the standards recommended by the Codex Alimentarius commission and also the Codex Code of Hygienic Practices for Foods for Infants and Children.

9. Continue feeding during illness and feed more after illness, Increase fluid intake during illness and also encourage the sick child to eat soft, varied, appetizing, foods.

\subsection{Infant and Young Child Feeding in Difficulties and Challenges in Ethiopia}

The problem of malnutrition in Ethiopia beginning early in life, primarily during the first 12 months, when growth faltering takes hold due to sub-optimal infant feeding practices. Once this growth faltering occurs, there is little opportunity for catch-up growth. Stunted infants grow to be stunted children and stunted adults. Thus, it is imperative to address issues of infant and young child feeding during the first year of life, particularly promoting proven optimal breast and complementary feeding practices.

In Ethiopia, 97 per cent of children are breastfed, only 58 per cent are exclusively breastfed during the first six months and only four per cent are fed four or more food groups. Only 45 per cent of children are fed at least three times a day. Micronutrient deficiencies in iron, vitamin A, folic acid, iodine and zinc remain the most common [21].

The low nutritional status among children has compromised the health of the children in Ethiopia, exposing them to poor health and early death. Ethiopia's infant mortality rate (77 per 1000 live births) and under-five mortality rate (123 per 1000 live births) are among the highest in Sub-Saharan Africa [22].

According to [22], the key factors contributing to under nutrition among children in Ethiopia are poverty, household food insecurity and low levels of maternal education. 79 percent of mothers of under-five children have never attended school, 19 percent have some primary education and only 4 percent have studied at the secondary level or higher. Children, whose mothers have not had any education, are twice as likely to be stunted and wasted and thrice as likely to be underweight, than children, whose mothers have been educated at the secondary level or higher.
In addition, the nutritional status of women is also a major problem in Ethiopia and contributes to the high levels of child malnutrition through inter-generational relationships. Thus it is imperative that any actions taken to address malnutrition in Ethiopia focus not only on infant feeding during the first year of life but also on nutritional improvements of adolescent girls and women of reproductive age.

Families in difficult situations require special attention and practical support to be able to feed their children adequately. In such cases, the likelihood of not breastfeeding increases, as do the dangers of artificial feeding and inappropriate complementary feeding.

Children living in special circumstances also require extra attention, for example, orphans and children in foster care, and children born to adolescent mothers, mothers suffering from physical or mental disabilities, drugs or alcohol dependence, or mothers who are imprisoned or part of disadvantaged or otherwise marginalized populations.

\subsection{Policy Gap in Ethiopia}

Ethiopian complementary food guide which says national strategy for infant and young child feeding and prepared by (Federal Democratic Republic of Ethiopia Ministry of Health, Ministry [20].

It is based on the international complementary food feeding guide line which mainly prepared by WHO. In the same matter it states all about the general criteria what every complementary food should have to full fill in terms of Energy content, protein vitamin and mineral content and the texture, viscosity of the porridge and consistency and variety of the food.

Additionally it includes the practical preparation guide line with the amount to be mixed, hygienic nature, the feeding style, and also the frequency of feeding per day.

Generally this guide line:

1. It is contains the general guide line it doesn't prepared based the dietary nature of the mothers and child (society). Because of different population has different access, culture, economy, they have different milk amount. However the amount of Energy and protein mainly depends on the amount breast feeding. So that the guide line should prepared base on the scientific research of dietary nature most societies of Ethiopia.

2. Vitamin -mineral supplementation and food fortification is the basic one to be nutritious complementary food. For example due to bio availability of Zinc and Iron, one infant couldn't meet his nutritious requirement until the food fortified by this minerals or get supplementation.

Interest in micronutrient malnutrition has increased greatly over the last few years. One of the main reasons for the increased interest is the realization that micronutrient malnutrition contributes substantially to the global burden of disease. Iodine, iron, vitamin-A and zinc deficiencies as being among the world's most serious health risk factors [22]. 


\subsection{Selection of Complementary Foods}

Improper food selection at this stage is associated with a high prevalence of malnutrition in children under 5 years, [23]. The adequate complementary feeding of the breastfed child is critical for the optimal child growth and development. Therefore, it is an essential factor for both the populations' food security and the development of nations [8].

It is important to guarantee the offer, every day if possible, of foods of animal origin rich in iron and of fruit and vegetables, especially those rich in vitamin a Non-fortified or no supplemented vegetarian diets are not recommended for infants younger than two years because they do not meet the requirements of some nutrients, such as iron, zinc and calcium.

It is not advisable to give infants younger than one-year unmodified cow's milk, especially if raw and undiluted, because its use is associated with blood loss in the stools and iron deficiency. Avoid offering sugary beverages (soft drinks and others), as they reduce the infant's appetite for more nutritious foods and may soften the stools. Tea and coffee are also inadvisable because they may interfere with iron up take [3].

\subsection{Some Good Complementary Foods in Ethiopia}

Good complementary foods which are energy-rich, nutrient-rich, locally available and affordable, include thick cereals with added oil or milk; fruits, vegetables, pulses, meat, eggs, fish, and milk products. Additional options include mashed potatoes softened with milk, shiro fitfit, merek fitfit, and porridge made of a mixture of grains and legumes with butter or oil added.

Nutritious complementary feeding recipes that can be prepared from locally available cereal foods for three major staple eating areas of the Ethiopian country, including:

Staple Group 1: Maize/Enset.

Staple Group 2: Teff/wheat/barley.

Staple Group 3: Maize/sorghum.

Source (Federal Democratic Republic of Ethiopia Ministry of Health, [20].

\subsection{Fortified Complementary Foods}

Fortified Complementary Foods are specifically formulated with appropriate nutritional quality to provide additional energy and nutrients to complement the family foods derived from the local diet by providing those nutrients which are either lacking or are present in insufficient quantities typically, cereal-based porridges with added vitamins and minerals [23].

According to [24] Home fortification is an innovation aimed at improving diet quality of nutritionally vulnerable groups, such as young children. It is typically done with Micronutrient Powders (MNP). The term Micronutrient Powders (MNP) refers to sachets containing dry powder with micronutrients that can be added to any semi-solid or solid food that is ready for consumption. Home fortification with
MNP aims to ensure that the diet, i.e. complementary foods and breast milk combined, meets the nutrient needs of young children.

Food fortification refers to addition of micronutrients into processed foods. It is a valid technology to improve micronutrient levels, as part of food-based approaches, if access to adequate levels of specific nutrients is limited [25].

Food fortification is an essential element in nutrition strategies to alleviate micronutrient deficiencies [26]. US Public Health Service recommended that all women capable of becoming pregnant consume $400 \mu \mathrm{g}$ of folic acid daily. Fortification of the food supply with folic acid presented an alternative approach to ensuring adequate intakes [27].

\section{Conclusion}

In conclusion, malnutrition among infants and young children is common in developing countries. In Ethiopia, mal-nutrition is the underlying causes of child morbidity and mortality, which contributes for more than $57 \%$ of deaths in under five years.

A proper complementary food is a food that comprises rich in energy, micronutrients (especially iron, zinc, calcium, vitamin $\mathrm{A}$, vitamin $\mathrm{C}$ and folates), free of contamination (pathogens, toxins or harmful chemicals), without much salt or spices, easy to eat, easily accepted by the infant, in an appropriate amount, easy to prepare from family foods, and at a cost that is acceptable by most families.

The production of the Guidelines has been the result of a long process that started in 2002. Under the aegis of the World Health Organization (WHO), an expert group was established and charged with the task of developing a set of guidelines on food fortification practice as international, But Because of there is so much variability in complementary food diets in different parts of the world, it is not feasible to provide global dietary "prescriptions" that would guarantee adequate intake of all essential nutrients. It is preferable to develop population-specific dietary guidelines for complementary foods based on the food composition of locally available foods.

In Ethiopia complementary feeding guide line was prepared based on the international complementary food feeding guide line which mainly prepared by WHO. generally it focuses on the criteria what every complementary food should have to full fill in terms of Energy content, protein vitamin and mineral content and the texture, viscosity of the porridge and consistency and variety of the food and its practical home preparation. Specifically it didn't prepared based on the dietary nature of the mothers and child (society).

Inadequate knowledge of the society about appropriate foods and feeding practices is often a greater determinant of malnutrition than the lack of food. Diversified approaches are also required to ensure access to foods that will adequately meet the energy and nutrient needs of growing children, the use of home and community based technology to enhance nutrient density, bioavailability and the micronutrient content of local foods. 


\section{Recommendation}

Although the challenges to improve nutrition are significant and may appear overwhelming, guide line should prepared base on the scientific research of dietary nature most societies of Ethiopia. And also add to the policy the way how the law income mother and infants gets this vitamin- mineral supplementation or micro nutrient powder (MNP) for homemade fortification in free from their nearby healthy station.

Measures to correct micronutrient deficiencies at least the major ones, Should have to build fortified complementary food product magazine in local woreda and distribute to the breast feeding infants in free.

Infant nutrition worker (health extension) who can follow up and guide complementary feeding practice in his/her kebele should be assigned.

Develop the knowledge of the society about appropriate foods and feeding practices by giving trainings and workshops.

So Sound and culturally appropriate nutrition counseling should be given to mothers of young children so that they can make the widest possible use of indigenous, locally available foods which are safely prepared and fed in the home.

Formulation of complementary food that is rich in protein, carbohydrate, fat and another nutrient at an adequate proportion to complement breast milk will bring about the end of the children high mortality rate and also, to reduce the incidence of malnutrition, the formulation and development of nutritious complementary food from local and readily available crops haves resaved a lot of attention.

Nutritional adequacy of complementary foods of different strategies may be required for different populations (e.g. rural vs. urban populations, the very poor, populations affected by emergencies), however among all these groups locally available foods should be exploited whenever possible.

\section{Appendix}

$\begin{array}{ll}\text { ACC } & \text { Administrative Committee on Coordination } \\ \text { AI } & \text { Adequate intake } \\ \text { EDHS } & \text { Ethiopia Demographic and Health Survey } \\ \text { DRI } & \text { Dietary reference intake } \\ \text { FAO } & \text { Food and Agriculture Organization } \\ \text { GAIN } & \text { Global Alliance for Improved Nutrition } \\ \text { IYCF } & \text { Infant and Young Child Feeding } \\ \text { MNP } & \text { Micronutrient Powders } \\ \text { PAHO } & \text { Pan American Health Organization } \\ \text { RDA } & \text { Recommended dietary allowance } \\ \text { SCN } & \text { Sub-Committee on Nutrition } \\ \text { SD } & \text { Standard Definition } \\ \text { UNCEF } & \text { United Nations International Children's } \\ \text { WHO } & \text { Emergency Fund } \\ \end{array}$

\section{References}

[1] ACC/SCN, "Fourth Report on the World Nutrition Situation.," Geneva ACC/SCN Collab. With IFPRI, p. 140, 2000.

[2] World Health Organization, "Global Nutrition Targets 2025: Breastfeeding policy,” W. H. O Publ., pp. 1-7, 2014.

[3] Renoos, "Complementary feeding or Weaning," CheenaChatti, 2013.

[4] C. K. Lutter and K. G. Dewey, "Proposed Nutrient Composition for Fortified Complementary Foods," J. Nutr., vol. 133, no. 9, pp. 3011S-3020S, 2018.

[5] Mensah, "infant meals," 1995.

[6] E. R. J. Giugliani and C. Gomes Victora, "Jornal de Pediatria Complementary feeding,” J. Pediatr. (Rio. J), vol. 76, no. 3, pp. 253-253, 2000

[7] A. Kolm, A. Hitthaller, P. Ruso, and E. Höld, "Einflussfaktoren auf das Beikostverhalten: Teil 1: übersicht zur Datenlage in europäischen Studien," Ernahrungs Umschau, vol. 63, no. 6, pp. M328-M334, 2016.

[8] C. M. G. Monte and E. R. J. Giugliani, "Recommendations for the complementary feeding of the breastfed child," J. Pediatr. (Rio. J), vol. 80, no. 8, pp. 131-141, 2007.

[9] C. West, "Introduction of Complementary Foods to Infants," Ann. Nutr. Metab., vol. 70, no. 2, pp. 47-54, 2017.

[10] A. Hörnell, H. Lagström, B. Lande, and I. Thorsdottir, "Breastfeeding, introduction of other foods and effects on health: a systematic literature review for the 5th Nordic Nutrition Recommendations," Food Nutr. Res., vol. 57, no. 1, p. 20823, 2013.

[11] UNICEF, “Appropriate complementary foods,” 2005.

[12] Kathyrn Dewey, "Guiding Principles for C O M P L E M E N Ta Ry Feeding of the Breastfed Pa N a M E R I C a N H E a Lt H O R G a N I Z At I O N," J. Clin. Nutr. Clin. Nutr., pp. 18-25, 2001.

[13] E. Grellety et al., "No Covariance structural analysis on health related indicators in the elderly at home focusing on subjective health sensation Title," Food Nutr. Bull., vol. 12, no. 3, p. 210, 2015.

[14] F. O. R. Americans, "DIETARY GUIDELINES,” 2020.

[15] S. A. Abrams and S. A. Atkinson, "Calcium, Magnesium, Phosphorus and Vitamin D Fortification of Complementary Foods," J. Nutr., vol. 133, no. 9, pp. 2994S-2999S, 2018.

[16] N. A. P. (US), "Dietary Reference Intakes for Calcium and Vitamin D," 2011.

[17] Nutrition guide line, "Nutrition guide line," 2015.

[18] WHO and FAO, "Older Infants and Young Children reference daily requirements for some vitamins and Minerals," 2006.

[19] H. Survey, "Children 's Health and Nutritional Status," 2011.

[20] F. Ministry, "National Strategy for Infant and Young," Heal. (San Fr., no. April, 2004.

[21] U. Ethiopia, "Infant and Young Child Feeding in Difficulties in Ethiopia," 2017. 
[22] B. Ljungqvist, W. S. From, and E. Asmare, "Final Report A SITUATION ANALYSIS OF NUTRITION IN ETHIOPIA POLICY AND PROGRAM OPTIONS,” no. August, 2015.

[23] P. Sen, A. Mardinogulu, and J. Nielsen, "Selection of complementary foods based on optimal nutritional values.," Sci. Rep., vol. 7, no. 1, p. 5413, 2017.

[24] Global Alliance for Improved Nutrition (GAIN), "Nutritional Guidelines for Complementary Foods and Complementary
Food Supplements Supported by GAIN," Glob. alliance fro Improv. Nutr., vol. 1, pp. 1-23, 2003.

[25] J. R. Arthur, R. C. Mckenzie, and G. J. Beckett, "Guidelines on food fortification with micronutrients," J. Nutr., vol. 133, pp. 1457-1459, 2003.

[26] T. H. Hunger and A. T. Scale, "Food fortifi cation: the unfi nished agenda," no. November, pp. 1-10, 2018.

[27] "Human Vitamin and Mineral Requirements." 